\title{
CAPÍTULO 24: REAPROVEITAMENTO DE RESÍDUOS NA CADEIA AGROINDUSTRIAL DO PESCADO: UMA REVISÃO
}

\author{
CAPÍTULO 24: REUTILIZACIÓN DE RESIDUOS EN LA CADENA \\ AGROINDUSTRIAL PESQUERA: UNA REVISIÓN
}

\section{CHAPTER 24: REUSE OF WASTE IN THE FISH AGROINDUSTRIAL CHAIN: A REVIEW}

\author{
Diana Carla Fernandes Oliveira ${ }^{1}$; Francielly Corrêa Albergaria ${ }^{2}$; Anderson Henrique Venâncio ${ }^{3}$; Maria Emília de \\ Sousa Gomes ${ }^{4}$; Rilke Tadeu Fonseca de Freitas ${ }^{5}$
}

\section{DOI:https://doi.org/10.31692/978-65-88970-19-5.369-388}

\section{RESUMO}

O setor pesqueiro consiste em uma atividade econômica de grande importância no Brasil e no mundo. Entretanto, com esse crescimento, surgem problemas relacionados à destinação dos resíduos sólidos (escamas, peles, carcaças, vísceras, cabeças) produzidos pela cadeia produtiva do pescado. Atualmente, um dos principais obstáculos da cadeia produtiva é o reduzido aproveitamento do resíduo gerado a partir do processamento do pescado. Estima-se que $50 \%$ da matéria-prima processada seja responsável pela geração de resíduos e o descarte inadequado pode ocasionar sérios impactos ambientais.O aproveitamento deste material é importante, pois trata se de proteína animal de excelente qualidade nutricional, com a utilização de diversas tecnologias esses resíduos podem ser destinados para: consumo humano, ração para animais, fertilizantes, produtos químicos, produção de biofilmes e embalagens. A utilização de resíduos comestíveis, além de diminuir custos e aumentar a eficiência de produção, minimiza os problemas de poluição ambiental oriundos da falta de destino adequado. $O$ presente artigo tem como objetivo realizar uma revisão de literatura sobre o reaproveitamento de resíduos da indústria pesqueira.

Palavras-Chave: Beneficiamento, Pescado, Processamento, Sustentabilidade

\section{RESUMEN}

El sector pesquero constituye una actividad económica de gran importancia en Brasil y en el mundo. Sin embargo, con este crecimiento, surgen problemas relacionados con el destino de los residuos sólidos (escamas, pieles, canales, vísceras, cabezas) producidos por la cadena producción pesquera. Actualmente, uno de los principales obstáculos en la cadena productiva es el reducido uso de residuos generados por el procesamiento del pescado. Se estima que el $50 \%$ de la materia prima procesada es responsable de la generación de residuos y una disposición inadecuada puede ocasionar graves impactos ambientales. El uso de este material es importante, por tratarse de proteína animal de excelente calidad nutricional, con el uso de diversas tecnologías estos residuos pueden ser destinados a: consumo humano, alimentación animal, fertilizantes, químicos, producción de biofilms y empaques. El uso de residuos comestibles, además de disminuir costos y aumentar la eficiencia productiva, minimiza los problemas de contaminación ambiental derivados de la falta de un destino adecuado.

\footnotetext{
${ }^{1}$ Pós-Graduação em Zootecnia, Universidade Federal de Lavras, diana_zootecnista@yahoo.com.br

${ }^{2}$ Pós-Graduação em Ciência dos Alimentos, Universidade Federal de Lavras, franalbergaria@hotmail.com

${ }^{3}$ Pós-Graduação em Ciência dos Alimentos, Universidade Federal de Lavras, anderson123dfgh21@gmail.com

${ }^{4}$ Professora, Departamento de Ciência dos Alimentos, Universidade Federal de Lavras, maria.emilia@ufla.br

${ }^{5}$ Professor, Departamento de Zootecnia, Universidade Federal de Lavras, rilke@ufla.br
} 
Este artículo tiene como objetivo realizar una revisión de la literatura sobre la reutilización de residuos de la industria pesquera.

Palabras Clave: Procesamiento, Pescado, Procesamiento, Sostenibilidad

\section{ABSTRACT}

The fishing sector consists of an economic activity of great importance in Brazil and in the world. However, with this growth, problems are arise regarding to the destination of solid residues (scales, skins, carcasses, viscera, heads) produced by the fish production chain. Currently, one of the main obstacles in the production chain is the reduced use of waste generated from fish processing. It is estimated that $50 \%$ of the raw material processed is responsible for the generation of waste and improper disposal can cause serious environmental impacts. The use of this material is important, as it is animal protein of excellent nutritional quality, with the use of several technologies these residues can be destined for: human consumption, animal feed, fertilizers, chemicals, production of biofilms and packaging. The use of edible waste, in addition to reducing costs and increasing production efficiency, minimizes environmental problems pollution arising from the lack of a suitable destination. This article aims to conduct a literature review on the reuse of waste from the fishing industry.

Keywords: Processing, Fish, Processing, Sustainability

\section{INTRODUÇÃO}

A indústria de beneficiamento de pescado constitui-se em uma das principais atividades econômicas de diversos países, sendo a proteína do pescado considerada uma fonte essencial de nutrientes (PIRES et al., 2014), contêm, grandes quantidades de vitaminas lipossolúveis (A e D) e minerais, além de possuir uma das mais importantes fontes protéicas de alto valor biológico com maior digestibilidade (SOARES \& GONÇALVES, 2012). A composição lipídica dos peixes contrasta com a de mamíferos por conter elevada proporção de ácidos graxos poli-insaturados de cadeia longa (SARTORI \& AMANCIO, 2012).

Em nível mundial, o pescado provê em torno de $17 \%$ do consumo total de proteína animal para 4,3 bilhões de indivíduos (TAHERGOABI et al., 2013). Entretanto, aproximadamente $60 \%$ do pescado processado é responsável pela geração de resíduos, enquanto apenas 40\% é designado para o consumo humano (CHALAMAIAH et al., 2012).

O Brasil é uma das principais potências no que diz respeito à indústria da pesca e consequentemente gera um alto índice de resíduos, podendo variar entre 50\% e 70\% do peso fresco, de acordo com cada espécie (COSTA, 2012; HE et al., 2013; SILVA et al., 2014). Entretanto, no setor produtivo brasileiro, o aproveitamento de resíduos da indústria pesqueira não é uma prática recorrente (SUCASAS, 2011). Estes resíduos são principalmente vísceras, cauda, coluna vertebral, barbatana, escamas e restos de carne (FELTES et al., 2010). Os principais destinos desses resíduos são os aterros sanitários e o 
descarte direto em rios e mares, os quais causam sérios problemas ambientais (REBOUÇAS et al., 2012) e econômicos que podem afetar a viabilidade da pesca e da indústria aquícola

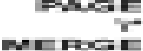

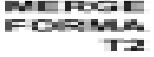
(ZAMORA-SILLERO et al., 2018).

Contudo, esses resíduos apresentam alto valor nutricional que, quando ocorre o aproveitamento de seu potencial. Com base no exposto, tem havido estudos e investigações direcionadas a encontrar novas formas de exploração de resíduos de pescado, a fim de minimizar os problemas ambientais (SHERIFF, SUNDARAM, RAMAMOORTHY, \& PONNUSAMY, 2014), agregam valor ao produto final gerando lucro e diminuindo o impacto ambiental (AGUIAR; LIMBERGER; SILVEIRA, 2014). Uma quantidade significativa de resíduos que podem ser direcionados para várias modalidades de aproveitamento: alimentos para consumo humano e consumo animal, fertilizantes ou adubos orgânicos, produtos químicos e ainda aproveitá-los no desenvolvimento de produtos funcionais, sendo uma grande parte destinada à produção de farinha (GONÇALVES, 2011).

No que diz respeito a produção aquícola marinha brasileira, a mesma pode ser dividida basicamente em dois tipos: a malacocultura, que se refere à produção de moluscos, e a carcinicultura, que se refere à produção de crustáceos.

O cultivo de moluscos tem crescido progressivamente, no entanto, a deposição de conchas que restam após a retirada dos moluscos em locais inapropriados, causa grave impacto ambiental e econômico (PIRES et al., 2014). Tristão et al. (2009) avaliaram a viabilidade técnica deste material ser utilizado para a fabricação de cal e a posterior produção de argamassa, demonstrando que estes resíduos atendem aos pré-requisitos para tal fabricação, sendo, portanto, possível realizar seu reaproveitamento.

Considerando o crescimento da produção de pescado, a importância socioeconômica da cadeia produtiva, assim como a problemática da geração de resíduos sólidos, objetivou-se realizar uma revisão de literatura acerca da geração de resíduos na indústria do pescado e as opções para o correto aproveitamento deste material, contribuindo para a sustentabilidade da pesca e aquicultura.

\section{METODOLOGIA}

O estudo foi desenvolvido mediante uma revisão de literatura científica, abordando temas referentes ao reaproveitamento de resíduos na cadeia agroindustrial do pescado. Realizou-se uma pesquisa bibliográfica abrangente usando bases de dados de literatura 
científica: Science Direct, Scopus, Scielo e Periódicos Capes, com os seguintes descritores: reaproveitamento de pescado, resíduos de peixes, processamento de pescado, coprodutos de pescados. Os trabalhos encontrados passaram por uma análise de título e resumo para refinar os artigos que estavam relacionados ao tema. Foram excluídos do presente estudo trabalhos que não apresentassem texto completo, que não estivessem publicados em revistas indexadas, e que não se adequassem ao tema abordado.

\section{PRODUÇÃO E CONSUMO DE PEIXE}

A aquicultura é um dos setores de produção de proteína animal que mais cresce em relação a outros setores do mesmo segmento (GODOY et al., 2013; LI \& PONZONI, 2015). Atualmente, o mercado global de alimentos vem sofrendo grandes mudanças nos padrões alimentares, gerando aumento na procura por alimentos de melhor qualidade nutricional, dentre eles o pescado (ZANARDI, 2011).

A produção global de peixes atingiu cerca de 179 milhões de toneladas em 2018, segundo estimativas da Organização das Nações Unidas para a Agricultura e Alimentação (FAO, 2018) das quais 82 milhões de toneladas são provenientes da aquicultura. A Piscicultura brasileira produziu 722.560 toneladas de peixes de cultivo em 2018, esse resultado é 4,5\% superior ao de 2017 (691.700 t) (PEIXE BR, 2020), sendo a tilápia a espécie mais produzida. Atualmente, a produção atingiu 486.155 toneladas, consolidando o Brasil como o quarto maior produtor de tilápias (PEIXE BR, 2021).

Apesar dos benefícios do pescado já terem sido comprovados, o consumo em muitos países ainda é a baixo. O recomendado pela Organização Mundial da Saúde (OMS) é de no mínimo de $12 \mathrm{~kg}$ / hab/ano, entretanto, no Brasil, em 2013, o consumo per capita de pescado foi de 10,87 kg/hab/ano (FAOSTAT, 2016). Segundo a FAO (2020) os dados globais sobre o consumo de peixe ocultam considerável variação regional. As diferenças nos níveis de renda também representam um fator importante nas diferenças de consumos, assim como disponibilidade e preço de proteínas substituíveis (DOS SANTOS FOGAÇA et al., 2015).

Melhorias na manipulação, no processamento para comercialização são fatores que favorecem a expanão, aumentam a qualidade dos produtos e reduz as perdas e despesas de produção (CHOWDHURY et al., 2010). Contudo, faz-se necessário a aplicação de estratégias políticas, científicas e empresariais que realmente incentivem o consumo de pescado no Brasil (GONÇALVES, 2011). Para tanto, é fundamental que ocorra um esforço conjunto entre 
produtores, comerciantes, órgãos governamentais e consumidores, com o propósito de exigir e assegurar melhor qualidade do produto disponível no mercado, a um preço acessível (OETTERER; GALVÃO; SAVAY-DA-SILVA, 2014).

\section{APROVEITAMENTO DE RESÍDUOS}

Por definição, resíduo é todo material que não é aproveitado durante a produção ou consumo, devido a limitações tecnológicas ou mercadológicas, que não apresenta valor de uso ou mercado, podendo resultar em danos ao meio ambiente quando não manejado de forma adequada (SUCASAS, 2011; REBOUÇAS et al., 2012; PIRES et al., 2014).

Durante o processo de beneficiamento do pescado (Figura 1), são gerados diversos resíduos, os coprodutos obtidos em termos percentuais são compostos de cortes musculares (15-20\%), pele e barbatanas (1-3\%), ossos (9-15\%), cabeças (9-12\%), vísceras $(12-18 \%)$ e escamas (5\%) (MARTÍNEZ-ALVAREZ, CHAMORRO, \& BRENES, 2015 ).

Figura 1. Fluxograma geral do processo de beneficiamento de pescados, com a indicação do processamento (setas contínuas) e dos resíduos gerados (setas pontilhadas).

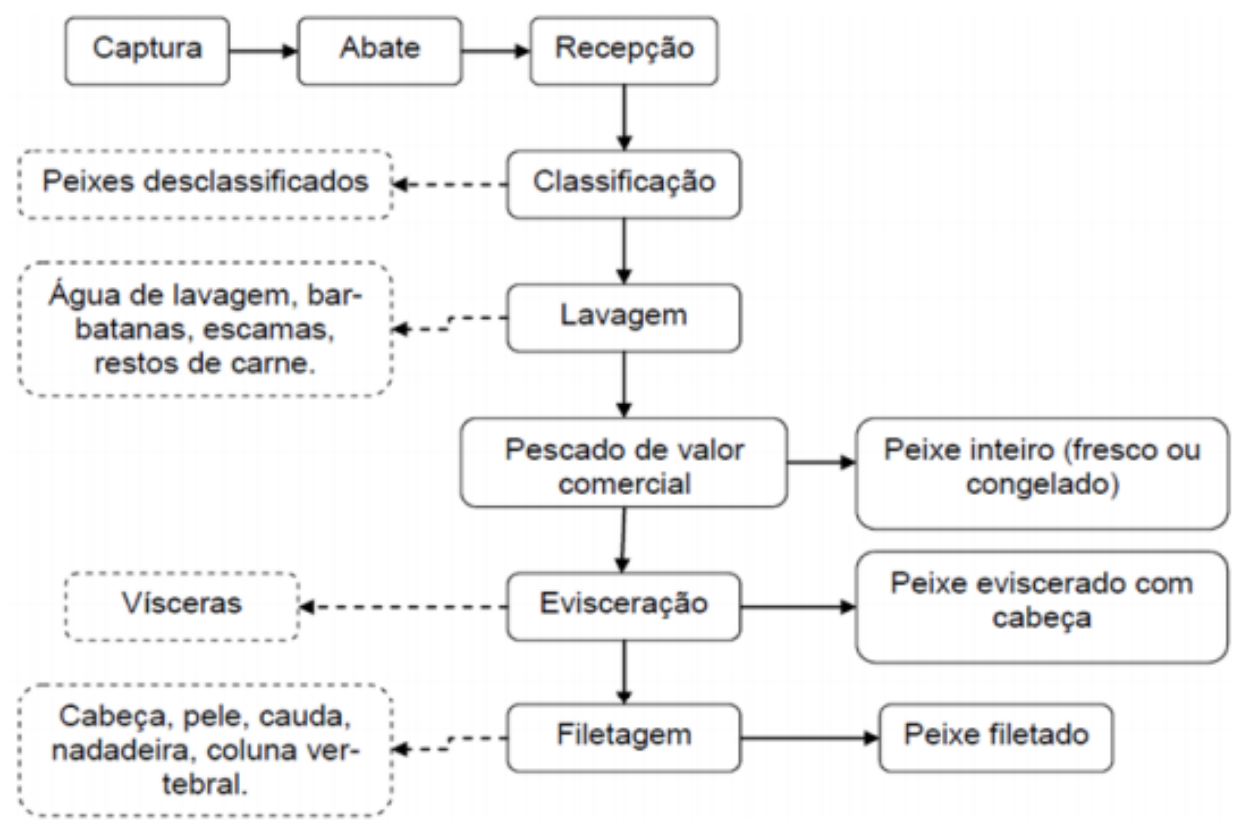

Fonte: Adaptado de Feltes et al. (2010).

O aumento da produção e do consumo de pescado está diretamente ligado à necessidade de se viabilizar tecnologias para o reaproveitamento dos resíduos gerados pela indústria aquícola. Na Figura 2 são apresentados os principais saídas de potenciais industriais 


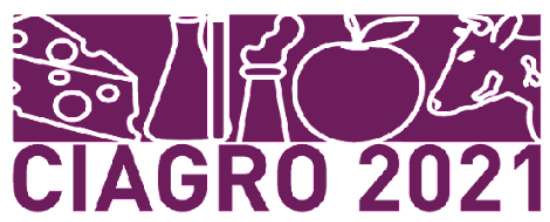

para os resíduos de peixes. Dos subprodutos obtidos após o processamento do pescado, uma grande variedade de compostos de alta qualidade pode ser recuperada e usada para consumo $P=-15$ humano e alimentação animal (VÁZQUEZ et al., 2019).

A maior parte dos resíduos destina-se à produção de farinha de peixe (NUNES, 2011; VIDOTTI; GONÇALVES; MARTINS, 2011; HU et al., 2013) e óleo (PRENTICE-HERNÁNDEZ, 2011; GONÇALVES; FERROLI; VIEGAS, 2012), para a produção de ração animal (BOSCOLO et al., 2010), reduzindo os custos de produção. Entretanto, os resíduos da industrialização podem ser direcionados para diversas modalidades de aproveitamento, tais como: alimentos para consumo humano (MAHBOOB, 2015; RADZIEMSKA et al., 2019; YUVARAJ et al., 2019; GOVINDHARAJ; ROOPAVATH; RATH, 2019; NAWAZ et al., 2020); fertilizantes de sistemas agrícolas (LÓPEZ-MOSQUERA et al., 2011), silagem e compostos (VIDOTTI, 2011; OLIVEIRA et al., 2014) ou hidrolisados (DIETERICH, 2014; FERREIRA et al., 2020); extração de colágeno (escamas e pele) para indústria farmacêutica e alimentícia.

Figura 2. Diagrama esquemático e resultados possíveis de um peixe durante o processamento.

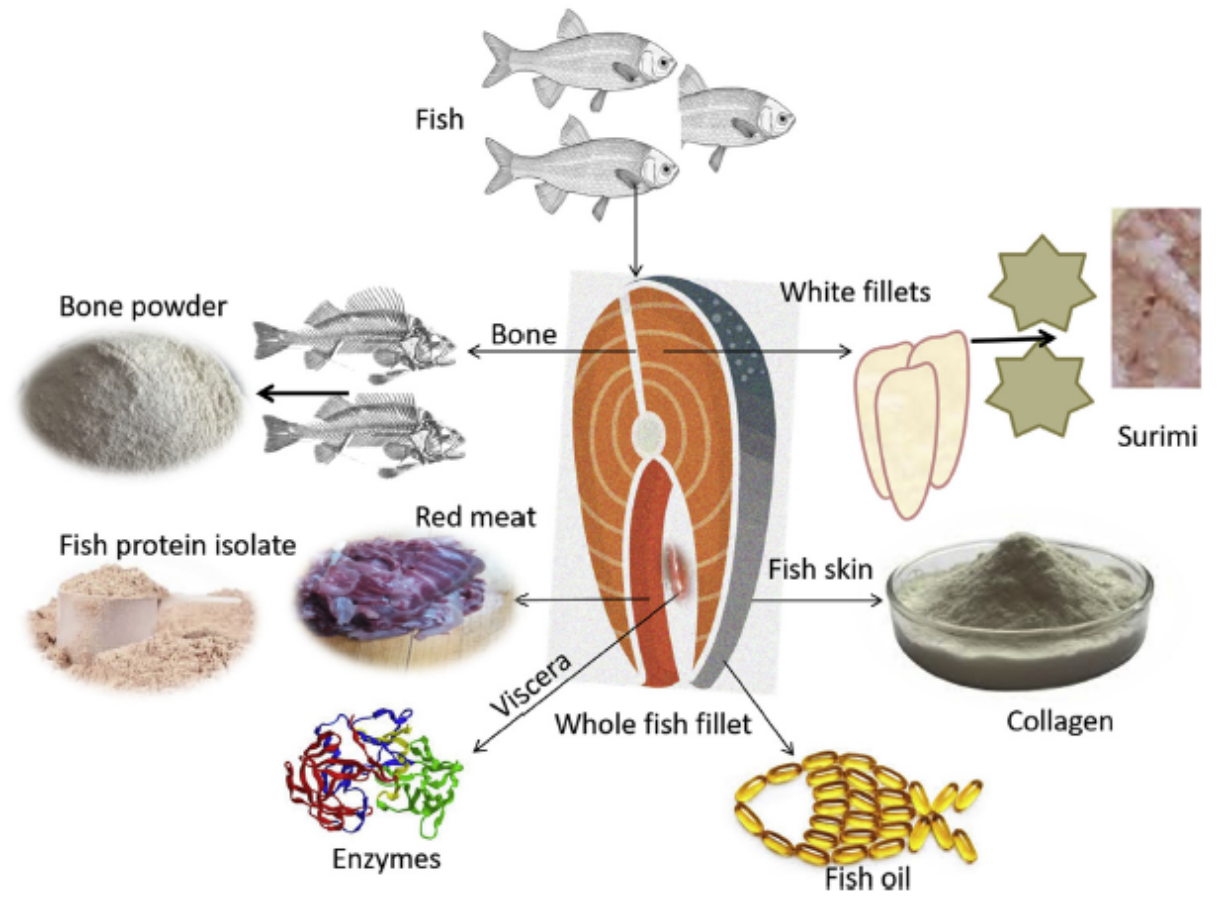

Fonte: NAWAZ et al., 2020

\section{APROVEITAMENTO PARA ALIMENTAÇÃO HUMANA}

Em geral, durante o beneficiamento de pescados, gera-se uma quantidade expressiva 
de resíduos que podem ser encaminhados para várias modalidades de aproveitamento. $\mathrm{O}$ desenvolvimento de novos produtos industrializados de maior valor agregado, evita desperdícios (GONÇALVES 2011). Com o uso de máquinas tecnológicas, é possível a aplicação do processo de extração de carne mecanicamente separada (KIRSCHNIK, 2007). Tal processo é capaz de recuperar grande parte da carne ainda aderida na carcaça (OLIVEIRA et al., 2012). A partir da carne mecanicamente separada (CMS) de peixe é possível desenvolver variedades de produtos e outras preparações que forneçam energia e que favoreçam a boa aceitação do produto pelo público em geral (BOSCOLO et al., 2009; FREITAS et al., 2012). Pode ser utilizada inclusive para a produção de farinha (DE MELO, 2018).

A CMS Pode ser utilizada como base em diferentes formulações, de forma a agregar valor ao produto final, como "fishburgers" (MARENGONI et al., 2009), almôndegas (OLIVEIRA et al., 2012; LUSTOSA-NETO et al., 2018); empanados (SIGNOR et al., 2020); patês (FREITAS et al., 2012); croquete (BORDIGNON et al., 2010); biscoito (NEIVA et al., 2011); mortadela (MELO et al., 2011) ; salsisha (LAGO et al., 2018); quenelle (ANGELINI et al., 2013) e também na produção de farinha através da secagem em um secador de circulação forçada (OLIVEIRA et al., 2015).

Nesse sentido, alguns autores se beneficiaram da utilização da farinha de peixe no enriquecimento de pães (BASTOS et al., 2014; SHANKAR), biscoitos e bolachas, caldo e sopa (BARRETO; ROCHA; LEDO, 2015), macarrão (GOES et al., 2016). Veit et al. (2012) estudaram a adição de $20 \%$ e $12 \%$ de filés de tilápia cozidos e triturados em bolo de chocolate e cenoura respectivamente. Essa é uma excelente estratégia de aumentar a ingestão de peixe no país, haja visto que o consumo é abaixo do recomendado e onde atualmente as pessoas estão comprando mais produtos alimentícios industrializados e de fácil preparo (GOES et al., 2016).

A elaboração de pratos utilizando farinha de peixe na merenda escolar de escolas públicas têm sido sugerido por vários autores, de modo a oferecer um alimento com elevado teor nutricional (ROCHA et al., 2011). Godoy et al. (2010) avaliou a aceitação de caldos e canjas elaborados com farinhas aromatizadas, elaborados com resíduo da filetagem, desenvolvidas a partir de carcaças de tilápia, carpa e pacu defumados. Os caldos e as canjas elaborados a partir das farinhas aromatizadas tiveram boa aceitabilidade pelos consumidores, podendo ser empregados, no caso da farinha, no enriquecimento de produtos para consumo 


\section{humano (BARRETO; ROCHA; LEDO, 2015).}

Os pescados subutilizados de baixo valor econômico, espécies pelágicas de pequeno tamanho, que podem vir durante a despesca, podem ser aproveitados para a obtenção da Carne Triturada de Pescado (CTP). O produto é obtido através da passagem do filé sem pele e/ou aparas por um moinho elétrico comercial. A CTP é empregada na elaboração de diversos produtos, podendo ser adquirida a partir de uma única espécie ou de uma mistura de espécies com características sensoriais similares (NEIVA e GONÇALVES, 2011; PIRES et al., 2014).

\section{FARINHA DE PEIXE}

A farinha de peixe é obtida após moagem e secagem de diferentes espécies de peixes inteiros, restos de peixes ou outros subprodutos resultantes do processamento de peixes (PIRES et al., 2014). A elaboração da farinha de resíduos principalmente oriundos do processo de filetagem apresenta-se com baixo valor comercial ou descarte, sendo estes processados, agrega valor podendo ser aproveitados no processamento de farinha de peixe (FOLLMANN; CENTENARO, 2013). A farinha de peixe é o principal subproduto obtido no provesso de beneficamento do pescado, podendo ser utilizada tanto em alimentação humana, como sitado anteriormente, como para a alimentação animal.

$\mathrm{Na}$ aquicultura, como em qualquer cultura animal, a ração comercial corresponde a uma alta porcentagem dos custos (DANTAS FILHO, 2017; BELETE, 2015; BATALHA et al., 2017), ultrapassam 80\% dos custos de produção (BELETE, 2015; PEREA-ROMÁN et al., 2018). Por isso, faz-se necessário buscar alternativas de reduzir os custos com alimentação, com a substituições de matérias não tradicionais que muitas vezes são desperdiçadas ou descartada pela indústria do pescado, isso sem comprometer a dieta e o desempenho dos peixes.

Vários estudos têm sido realizados para identificar fontes proteicas alternativas que permitiriam uma redução no custo da alimentação e simultaneamente aproveitar resíduos agroindustriais (SILVA, 2016; BATALHA et al., 2017). A farinha de peixe é considerada a melhor fonte de proteína para peixes devido ao seu excelente perfil de aminoácidos, alto teor de proteína bruta, alta palatabilidade e alta digestibilidade (FRABEGAT et al., 2011).

\section{ÓLEO DE PEIXE}

O óleo de peixe é a fração lipídica extraída de peixes e subprodutos de 
peixes. Atualmente, a produção de óleo de peixe está se tornando mais exigente, visto que há uma demanda considerável e crescente no mercado mundial por óleos de peixe de alta qualidade. Além de seus vários usos como óleos consumíveis, também é apreciável tanto na indústria farmacêutica quanto na indústria (ABDULKADIR et al., 2010 ). Nos últimos anos, o óleo de peixe, fonte de ácido ômega-3, vem sendo utilizado para fins de suplemento e fortificação pelas indústrias farmacêutica (MOZZAFARIAN e WU, 2011) e alimentícias, sendo utilizado como óleo enlatado, para a produção de margarina e maionese (HERNANDEZ, 2011).

Segundo Aguiar, Limberger e Silveira (2014), os benefícios do óleo de peixe têm sido apontados em estudos recentes na alimentação de seres humanos e animais e isso está relacionado, pelo fato de este produto apresentar considerável interesse bioquímico, metabólico, nutricional e farmacêutico. O óleo de peixe é um ingrediente comumente usado na dieta de animais aquático devido ao seu alto valor nutricional, além de fornecer ácidos graxos essenciais, melhora a palatabilidade da ração (TANTIKITTI, 2014).

Outra alternativa para o aproveitamento do óleo de peixe seria para a produção de biodiesel. Gomes et al. (2015) extraíram lipídeos das vísceras de sardinha-verdadeira para produção de biodiesel. O óleo extraído apresentou um bom rendimento $(18,75 \%)$ para a produção de biodiesel.

\section{SILAGEM DE RESÍDUOS}

A silagem de pescado é definida como produto líquido, em primeira instância, no qual são adicionados ácidos, enzimas ou bactérias produtoras de ácido láctico, resultando na liquefação da massa (VIDOTTI, 2011), podendo ser oriunda do peixe inteiro ou partes dele (PANTOJA et al., 2011).

A fabricação de silagem a partir da comercialização de resíduos de processamento de pescado visando a obtenção de ingrediente alimentar de aquicultura tem sido amplamente estudada nos últimos anos (SILVA, 2016; BATALHA et al., 2017). Além do mais, o baixo custo do produto da silagem, especialmente quando comparado à farinha de peixe e/ou rações comerciais é bastante atraente (SALES; OLIVEIRA, 2015). Aplicada a pequenas unidades comerciais, a silagem representa uma proposta vantajosa em vista do crescente aumento de resíduos da industrialização do pescado (MAIA JÚNIOR e SALES, 2013), uma vez que sua fabricação não requer altos investimentos tampouco equipamentos específicos (ROMAN et 
al., 2017). Apesar das alterações que acontecem no processo de elaboração, as silagens de peixe conservam as suas características químicas e nutricionais semelhantes ao material de origem (VIDOTTI; GONÇALVES, 2006).

\section{COMPOSTAGEM DE RESÍDUOS}

O processo de compostagem é uma das formas mais empregada para o aproveitamento de resíduos, para atividades agrícolas, no entanto, existe outra forma de utilização destes resíduos, que é a fermentação do material (SANES et al., 2015). O composto resultante da fermentação aeróbica ou anaeróbica do resíduo de pescado, apresenta-se como uma viável fonte de nutrientes para sistemas produtivos de base ecológica.

Contudo, a compostagem de resíduso pesqueiros não é devidamente divulgada no Brasil pela falta de conhecimentos sobre os benefícios de utilização desses compostos (BARREIRA; PHILIPPI; RODRIGUES, 2005). Segundo Coelho (2008), a compostagem utiliza diferentes tipos de resíduos na produção de adubo, proporcionando melhores características de produtividade e qualidade do vegetal quando adicionado ao solo.

\section{BIOFILMES E EMBALAGENS}

A utilização de materias plásticos aumentou devido às suas boas propriedades, acessibilidade, facilidade de processamento, leveza e baixo custo. Entretanto, os materias plásticos são preparados por processo de plomerização por condensação ou polimerização de monômeros de diferentes hidrocarbonetos, todos têm origem na indústria petroquímica, o que os torna não renováveis e não biodegradáveis (COSTA et al., 2012). Atualmente, há uma demanda crescente de matérias-primas baseadas em biomaterias, a fim de reduzir os problemas de eliminação de resíduos (GARAVAND et al., 2017). Muitas dessas embalagens tem sido desenvolvida a partir de matérias-primas naturais e renováveis, como proteínas, polissacarídeos e lipídeos oriundos do reaproveitamento de resíduos de pescado (LECETA et al., 2014).

Neste contexto, a quitina e a quitosana (polissacarídeos), possuem grande valor no mercado, o que faz com que seja viável a obtenção a partir dos resíduos de pesca (RODRIGUES et al., 2020). Dentre suas várias aplicações, a quitosana pode ser designada para a produção de um polímero, denominado biofilme. O biofilme é um filme fino preparado a partir de materiais biológicos, que age como barreira a elementos externos e, 
consequentemente, pode proteger o produto embalado de danos físicos e biológicos e aumentar a sua vida útil. (HENRIQUE et al., 2008).

A quitina e seus derivados, têm muitas aplicações importantes nas áreas farmacêutica, alimentícia, agricultura, bioengenharia e cosméticos (DUAN et al., 2012). É encontrada comercialmente nos produtos de resíduos da indústria de processamento de alimentos marinhos (LIMAM et al., 2011), e apresenta diversas propriedades benéficas, tais como: anti-inflamatória (YANG et al., 2010); neuroprotetora (PANGESTUTI \& KIM, 2010); antitumoral (QUAN et al., 2009) e antifúngica e antibacteriana (FERNANDES et al., 2008).

As peles de pescado são uma valiosa fonte de obtenção de gelatina, que é uma proteína com diferentes propriedades funcionais e aplicações, incluindo a capacidade de formação de filme e aplicação como cobertura na proteção de alimentos (HOSSEINI et al., 2013). Entretanto, os filmes produzidos a partir da gelatina, possuem algumas desvantagens, como alta solubilidade em água e fracas propriedades mecânicas, o que limita sua faixa de aplicação e utilização. Contudo, o desempenho físico e microbiológico de filmes à base de gelatina de pescado podem ser melhorados através de combinação, em sua matriz, com outros materias renováveis de resíduos marinhos, como quitosana e ácidos graxos (LECETA et al., 2014; JRIDI et al., 2014; GÓMEZ-ESTECA et al., 2011).

\section{ARTESANATO E MODA}

$\mathrm{Na}$ sociedade atual, a pesca artesanal continua se reafirmando como atividade importante tanto do ponto de vista econômico (como geração de renda e produção de alimento) quanto social e culturalmente (COSTA et al., 2016). No Brasil, a utilização de escamas de peixe em artesanato é uma técnica que vem sendo difundida há pouco tempo, porém existem alguns projetos estão sendo desenvolvidos em comunidades como na de Barra de Serinhaém, em Ipojuca - PE (Figura 3). As escamas, avaliadas como produto de alta qualidade e durabilidade, contribuem para a geração de renda e equidade de comunidades que vivem da pesca artesanal.

Figura 3- Flores confeccionadas com as escamas de peixe, com destaque para a flor confeccionada em escama de camurupim na comunidade da Barra de Serinhaém, Ipojuca-PE. 

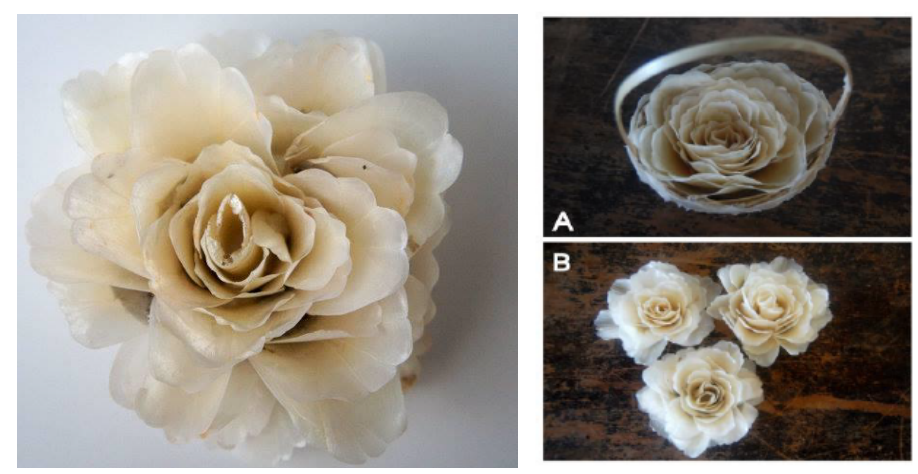

Fonte: (COSTA et al., 2016)

A indústria da moda sempre esteve entre as indústrias que mais emitem carga de resíduos ambientais. A pele de peixe surge, então, como uma nova alternativa para o design sustentável, constituindo-se como um material diferenciado e resistente, cujo processo de produção pode se adequar às leis de preservação e sustentabilidade, desde que o curtimento seja realizado de forma que não prejudique o meio ambiente (CARDOSO, 2010) (Figura 4).

Figura 4- Aspecto final após curtimento da pele de peixe.

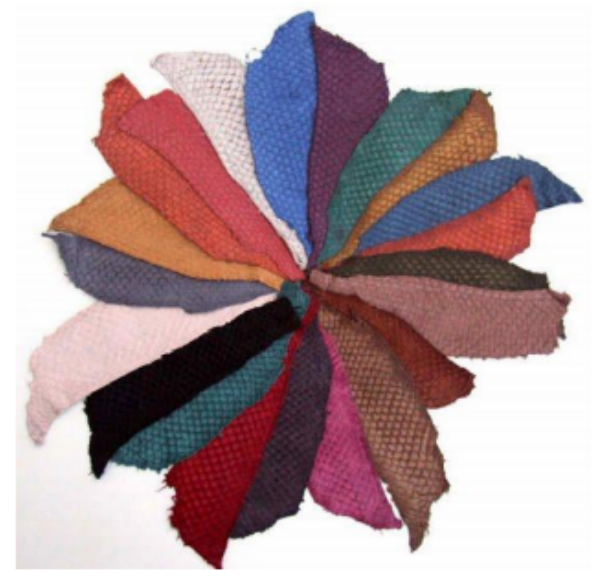

Fonte: Criecologico (2012)

Após passar por um processo de bebeficiamento têxtil, o couro de peixe se torna um objeto durável e resistente, apresentando o dobro de resistência do couto bovino. Entretanto, a resistência do couro é influenciada por fatores como a espécie do peixe, sua idade e peso, sentido da pele (transversal ou longitudinal em relação ao comprimento do peixe), conservação e processo de curtimento (NUPÉLIA, 2014). A existência de mercado consumidor para couro de peixes e seu potencial de crescimento, são os principais fatores de maior abrangência dessa oportunidade de negócio (SOUZA, 2010). 


\section{CONCLUSÕES}

A melhor forma de se destinar produtos de descarte de reíduos pesqueiros é, por meio do desenvolvimento de novos produtos. A elaboração dos mesmos é uma forma de reduzir os impactos negativos da atividade industrial ao meio ambiente, ao mesmo tempo, que pode ser uma provável solução para problemas de má nutrição, atribuídos à carência ou deficiência de proteínas de elevado valor nutricional na dieta alimentar. Embora diversas tecnologias se mostrem viáveis para a fabricação de subprodutos de alto valor agregado a partir dos resíduos de pescado, o mesmo ainda tem sido realizado de forma não recorrente.

\section{REFERÊNCIAS}

ABDULKADIR, M., Abubakar, GI, \& Mohammed, A. Produção e caracterização de óleos de peixes. Journal of Engineering and Applied Sciences, v.5, n. 7, p. 769-776, 2010.

AGUIAR, G. P. S.; LIMBERGER, G. M.; SILVEIRA, E. L. "Altermativas tecnológicas para o aproveitamento de resíduos provenientes da industrialização de pescados". Revista Eletrônica Interdisciplinar, Barra do Garça, v. 1, n. 11, p. 225-229, 2014.

ANGELINI, M. F. C. et al M. Shelf life and sensory assessment of tilapia quenelle during frozen storage. Pesquisa Agropecuária Brasileira, v. 48, n. 8, p. 1080-1087, 2013.

ARVANITOYANNIS, I. S. (2010). Waste management for the food industries. Academic Press.

BARREIRA, L.P.; PHILIPPI A.J.; RODRIGUES M.S. Usinas de compostagem: avaliação da qualidade dos compostos e processos de produção. 2005.

BARRETO, N., ROCHA, J. B. S.; LEDO, C. A. S. Elaboração de biscoitos e sopa usando farinha de peixe. 2015 .

BASTOS, S. C. et al. Resíduos da filetagem de peixes para enriquecimento de pão de trigo: características químicas e sensoriais. Jornal de ciência e tecnologia de alimentos , v. 51, n. 9, pág. 2240-2245, 2014.

BATALHA, S.S. et al Digestibility and physico-chemical characteristics of acid silage meal made of pirarucu waste in diets for commercial laying hens. Acta Scientiarum Animal Sciences, v.39, n.3, p.251-257, 2017.

BELETE, N.A.S. Impacto ambiental, desempenho produtivo e econômico do uso de diferentes taxas de alimentação no cultivo do pirarucu Arapaima gigas (CUVIER, 1829). 2015. 38f. Dissertação (Mestrado em Ciências Ambientais) - Universidade Federal de Rondônia, Rolim de Moura-RO, 2015. 
BELETE, N.A.S. Impacto ambiental, desempenho produtivo e econômico do uso de diferentes taxas de alimentação no cultivo do pirarucu Arapaima gigas (CUVIER, 1829). 2015. 38f. Dissertação (Mestrado em Ciências Ambientais) - Universidade Federal de Rondônia, Rolim de Moura-RO, 2015.

BORDIGNON, A. C. et al. Elaboração de croquete de tilápia do Nilo (Oreochromis niloticus) a partir de CMS e aparas do corte em "V" do filé e sua avaliação físico-química, microbiológica e sensorial. Maringá, v.32, n.1, p.109-116, 2010.

BORGHESI, R. et al. Influencia da nutrição sobre a qualidade do pescado: especial referência aos ácidos graxos- Corumbá : Embrapa Pantanal; Dourados : Embrapa Agropecuária Oeste, p. 21, 2013.

BOSCOLO, W. E. et al. Peixe na Merenda escolar: Educar e formar novos consumidores. GFM Gráfica e Editora Ltda Editoração. Toledo - PR, 2009.

CARDOSO, Juliana. O design industrial como ferramenta para a sustentabilidade: estudo de caso do couro de peixe. Revista espaço acadêmico, n114, novembro 2010.

CHAMALAIAH, M. et al. Fish protein hydrolysates: Proximate composition, amino acid composition, antioxidant activities and applications: A review. Food Chemistry, v. 135, p. 3020-3038, 2012.

COELHO, F.C. Composto Orgânico. Manual Técnico, 03. Niterói: Programa Rio Rural, 2008. COSTA, S. R; SOUZA, P. A. R. O impacto dos resíduos de pescado: o caso da "Feira do Bagaço" no município de Parintins no Amazonas. DELOS Revista Desarrollo Local Sostenible, v.5, n.14, p. $01-11,2012$.

COSTA, T. L. E. et al. Avaliação de coberturas comestíveis compostas por quitosana e argila no revestimento em tomates sob refrigeração pelo método dipping. Revista Verde de Agroecologia e Desenvolvimento Sustentável, p, 12-19, 2014.

COSTA, W. M. et al. Aproveitamento de resíduos de pescado: o artesanato com escamas de peixe. Rev. Ciênc. Ext. v.12, n.2, p.8-17, 2016.

Criecologico. Curtume de peixes. Dísponivel em: https://criecologico.blogspot.com/2010/05/reciclando-os-peixes.html. Acesso em: 10/04/2021.

DANTAS FILHO, J.V. Gestão de Custos na Piscicultura no Município de Presidente Médici-Rondônia-Brasil. AB Custos, v.12, n.2, p.29-53, 2017.

De MELO, M. P. F., SANTOS, A. D. S., PIRES, C. R. F., de ALMEIDA, H. C. G., \& de SOUSA, D. N. Desenvolvimento tecnológico e caracterização nutricional de massa alimentícia enriquecido com farinha de peixe. In Embrapa Pesca e Aquicultura-Artigo em anais de congresso (ALICE). In: SIMPÓSIO DE CONTROLE DE QUALIDADE DO PESCADO, 7., São Paulo, 2016. Estratégias para aumentar o consumo do pescado: proceedings. São Paulo: Instituto de Pesca, 2018. 
DIETERICH, F. et al. Development and Characterization of Protein Hydrolysates Originated from Animal Agro Industrial Byproducts. Journal of Dairy, Veterinary \& Animal Research, v. 1, p. 12-19, 2014.

DOS SANTOS FOGAÇA, F. H. et al. Caracterização de surimi obtido a partir da carne mecanicamente separada de tilápia do Nilo e elaboraçãso de fishburger. Semina:Ciencias Agrarias, v. 36, n. 2, p. 765-776, 2015.

DUAN, S. et al. Improved production of chitin from shrimp waste by fermentation with epiphytic lactic acid bacteria. Carbohydrate Polymers, v.89, n. 4, 1283-1288, 2012.

FAO. Food and Agriculture Organization of the United Nations. The State of World Fisheries and Aquaculture 2018 - Meeting the sustainable development goals. Roma, 2018. Disponível em: < http://www.fao.org/3/i9540en/I9540EN.pdf $>$. Acesso em 09/04/2021.

FAO. 2020. $A$ Situação Mundial da Pesca e Aquicultura 2020 .

FAOSTAT. Evolução do consumo de pescado per capita no Brasil. 2016.

FELTES, M. C.M. et al. Alternativas para a agregação de valor aos resíduos da industrialização de peixe. Revista Brasileira de Engenharia Agrícola e Ambiental, v.14, n.6, p.669-677, 2010.

FERNANDES, J.C. et al. Antimicrobial effects of chitosans and chitooligosaccharides, upon Staphylococcus aureus and Escherichia coli, in food model systems. Food Microbiology, v. 25, p. 922-928, 2008.

FERREIRA, H. K. A, et al. Hidrolisados proteicos de resíduos da indústria de processamento de tilápia: caracterização centesimal, microbiológica e aminoácidos. Brazilian Journal of Development, v. 6, n. 8, p. 59516-59527, 2020.

FOLLMANN, A. M. C., \& CENTENARO, A. I. Elaboração de bolo de laranja adicionado com diferentes concentrações de farinha de carcaça de Tilápia do Nilo (Oreochromis niloticus) (Bachelor's thesis, Universidade Tecnológica Federal do Paraná), 2013.

FREITAS, D.G.C.; RESENDE, A.L.S.S.; FURTADO, A.A.L.; TASHIMA, L.; BECHARA, H.M. The sensory acceptability of a tilapia (Oreochromis niloticus) mechanically separated meat-based spread. Brazilian Journal of Food Technology, 15: 166-173, 2012.

GODOY, L. C. et al. Análise sensorial de caldos e canjas elaborados com farinha de carcaças de peixe defumadas: aplicação na merenda escolar. Ciência e Tecnologia de Alimentos, v.30, p.86-89, 2010.

GODOY, L.C. et al. Development, Preservation, and Chemical and Fatty Acid Profiles of Nile Tilapia Carcass Meal for Human Feeding. Jour. Food Proc. Preser., v.37, p.93-99, 2013.

GOES, E. S. dos R. et al. Fresh pasta enrichment with protein concentrate of tilapia nutritional and sensory characteristics. Food Science and Technology, v. 36, n. 1, p. 76-82, 2016. 
GÓMEZ-ESTACA, J. Effects of gelatin origin, bovine-hide and tuna-skin, on the properties of compound gelatin-chitosan films. Food Hydrocolloids, v. 25, n. 6, p. 1461-1469, 2011.

GOMES, A. F; SANTOS, A. G. D; SOUZA, L. D; PINTO, C. H. C; MATIAS, L. G. O; BEATRIZ, A. Síntese e caracterização de biodiesel com material lipídico extraído das vísceras da Sardinella brasiliensis. Revista Geintec, v.5, n.2, p.2181-2194, 2015.

GONÇAlVES A. A. Tecnologia do Pescado: Ciência, Tecnologia, Inovação e Legislação. São Paulo: Editora Atheneu, 2011. 608 p.

GONÇALVES, L. U.; FERROLI, F.; VIEGAS, E. M. M. Effect of the inclusion of fish residue oils in diets on the fatty acid profile of muscles of males and females lambari (Astyanax altiparanae). Revista Brasileira de Zootecnia, Viçosa, MG, v. 41, n. 9, p. 1967-1974, 2012

GOVINDHARAJ, M.; ROOPAVATH, U. K.; RATH, S. N. Valorization of discarded Marine Eel fish skin for collagen extraction as a $3 \mathrm{D}$ printable blue biomaterial for tissue engineering. Journal of Cleaner Production, v. 230, p. 412-419, 2019.

GARAVAND, F. et al. Improving the integrity of naturak biopolymer films used in food packaging by crosslinking approach. A review. International Journal of Biological Macromolecules, v. 104, p. 687-707. 2017.

HERnANDEZ, C.P. Óleo de Pescado. In: GONÇALVES, A.A. Tecnologia do Pescado: Ciência, Tecnologia, Inovação e Legislação. São Paulo: Editora Atheneu, 2011. p.372-380.

HOSSEINI, S. F. et al. Preparation and functional properties of fish gelatin-chitosan blend edible films. Food Chemistry, v. 136, n. 3-4, p. 1490-1495, 2013.

HU, L. et al. Effects of fish meal quality and fish meal substitution by animal protein blend on growth performance, flesh quality and liver histology of Japanese seabass (Lateolabrax japonicas). Aquaculture, Amsterdam, v. 372-375, p. 52-61, 2013.

JRIDI, M. et al. Physical, structural, antioxidant and antimicrobial properties of gelatin-chitosan composite edible films, International Journal of Biological Macromolecules, v. 67, p. 373-379, 2014.

KIRSCHNIK, P. G. Avaliação da estabilidade de produtos obtidos de carne mecanicamente separada de tilápia nilótica (Oreochromis niloticus). 2007. 102 f. Tese (Doutorado em Aquicultura) - Universidade Estadual Paulista, Jaboticabal, 2007.

KUBITZA, F.; CAMPOS, J. L. O aproveitamento dos subprodutos do processamento de pescado. Panorama da Aquicultura, Laranjeiras, v. 16, n. 94, p. 23-29, 2006.

LAGO, A. M. T. et al. Fish sausages prepared with inclusion of Nile tilapia minced: Correlation between nutritional, chemical, and physical properties. Journal of Food Processing and Preservation, v. 42, n. 10, 2018. 
LECETA, I. et al. Biobased films prepared with by-products and wastes. Environmental assessment. Journal of Cleaner Production, v. 64, p. 218-227, 2014.

LI, Y \& PONZONI, R. W. Some aspects of design and analysis of selection programmes in aquaculture species. Journal of Animal Breeding and Genetics, v. 132, p.169-175, 2015.

LIMAM, Z.; SELMI, S.; SADOK, S.; EL-ABED, A. Extraction and characterization of chitin and chitosan from crustacean by-products: biological and physico-chemical properties. African Journal of Biotechnology, v.10, n.4, p. 640-647, 2011.

LÓPEZ-MOSQUERA, M. E. et al. Composting fish waste and seaweed to produce a fertilizer for use in organic agriculture. Procedia Environmental Science, Amsterdam, v. 9, p. $113-117,2011$.

LUSTOSA-NETO, A.D. Almôndegas de pirarucu e tilápia nilótica: caracterização e aplicação na merenda escolar, Acta of fisheries and aquatic resources, v. 6, n. 2, p. 1-12, 2018.

MAHBOOB, S. Isolamento e caracterização do colágeno de resíduos de peixes - pele, escamas e nadadeiras de Catla catla e Cirrhinus mrigala. Journal of Food Science and Technology , v. 52, n. 7, pág. 4296-4305, 2015.

MAIA JUNIOR, W. M. Adequação do processamento de silagens de resíduos de tilápia (Oreochromis niloticus Linnaeus, 1757): caracterização química e funcional da fração seca em pó e lipídios. 1998. Dissertação (Mestrado em Ciência e Tecnologia de Alimentos) Universidade Federal da Paraíba, João Pessoa.

MALUF, M. L. F.; HILBIG, C. C. Curtimento ecológico de peles de animais para agregação de valor através da confecção de artesanato. Revista Varia Scientia, Cascavel, v. 9, n. 15, p. 75-79, 2010.

MARTÍNEZ-ALVAREZ, O., CHAMORRO, S., \& BRENES, A. Protein hydrolysates from animal processing by-products as a source of bioactive molecules with interest in animal feeding: A review. Food Research International, v. P.73, 204-212, 2015.

MARENGONI, N. G. et al. Caracterização microbiológica, sensorial e centesimal de fishburgers de carne de tilápia mecanicamente separada. Revista Brasileira de Saúde e Produção Animal, v.10, n.1, p.168-176, 2009.

MÉLO, H. M. G. Viabilidade da utilização da carne mecanicamente separada (CMS) de Tilápia do nilo na elaboração de um produto tipo "mortadela". ARS Veterinaria, v. 27, n. 1, p. 22-29, 2011.

MOZZAFARIAN, D.; WU, J. H. Y. Omega 3 Fatty Acids and Cardiovascular Disease. Journal of the American College of Cardiology, v.58, n.20, p.2047-2067, 2011.

NAWAZ, A. et al. Valorização dos subprodutos da pesca: Desafios e preocupações técnicas para a indústria alimentar. Trends in Food Science \& Technology , v. 99, p. 34-43, 2020. 
NEIVA, C. R. P.; GONÇALVES, A.A. Carne Mecanicamente Separada (CMS) de Pescado e Surimi. In: GONÇALVES, A.A. Tecnologia do Pescado: Ciência, Tecnologia, Inovação e Legislação. São Paulo: Editora Atheneu, p.197-207, 2011.

NEIVA, C.R.P. et al. Fish crackers development from minced fish and starch: an innovative approach to a traditional product. Ciência e Tecnologia de Alimentos, v. 31, n.4, p. 973-979, 2011.

Núcleo de pesquisa nuélia. Disponível em: http://peixe.nupelia.uem.br. Acesso em $10 / 04 / 2021$.

NUNES, M. L. C. Farinha de pescado. In: GONÇALVES, A. A. Tecnologia do pescado: ciência, tecnologia, inovação e legislação. São Paulo: Atheneu, 2011. 608 p.

OETTERER, M.; BORGHESI, R.; ARRUDA, L. F. Como preparar a silagem de pescado. Série Produtor Rural. Piracicaba: ESALQ, n. 15, 2001. 16 p.

OETTERER, M.; GALVÃO, J. A.; SAVAY-DA-SILVA, L. K. Qualidade do pescado: sistemas para padronização. In: GALVÃO, J. A.; OETTERER, M. (Org.). Qualidade e processamento de pescado. 1 ed. Rio de Janeiro: Elsevier, p. 31-71, 2014.

OLIVEIRA, I.S. et al. Composition of MSM from Brazilian catfish and technological properties of fish flour. Food Control, 50: 38-44, 2015.

OLIVEIRA, M. C.; CRUZ, G. R . B; ALMEIDA, N. M. Características microbiológicas, físico-químicas e sensoriais de "almôndegas" à base de polpa de Tilápia (Oreochromis niloticus). Ciências Biológicas e da Saúde, v. 14, n. 1, p. 37-44, 2012.

OLIVEIRA, M.C.; CRUZ, G.R.B.; ALMEIDA, N.M. Características Microbiológicas, Físico-Químicas e Sensoriais de "Almôndegas" à Base de Polpa de Tilápia (Oreochromis niloticus). Revista Unopar Científica Ciências Biológicas e da Saúde, 14(1): 37-44, 2012.

OLIVEIRA, P. R. et al. Sensorial, físico -química e microbilógica do pirarucu (Arapaima gigas, Schinz, 1822) durante estocagem em gelo. Braziliam Journal of Food Technology. v.17, p. 67-74, 2014.

PANTOJA, A.O.; SANCHEZ, S.M.; HOYOS, J.L. Obtención de un alimento extruido para tilapia roja (Oreochromis spp) utilizando ensilaje biológico de pescado. Biotecnología em el Sector Agropecuário y Agroindustrial, v.9, n.2, 2011.

PEIXE BR. Associação Brasileira da Piscicultura. Anuário PeixeBR da Piscicultura 2020.

PEIXE BR. Associação Brasileira da Piscicultura. Anuário PeixeBR da Piscicultura 2021.

PEREA-ROMÁN, C. et al. Valoración económica del uso de ensilaje de residuos piscícolas en la alimentación de Oreochromis spp. Biotecnologia en el sector agropecuário y agroindustrial, v.16, n.1, p.43-51, 2018. 
PIMENTA, M. E. S. G.; FREATO, T. A.; DE OLIVEIRA, G. R. Silagem de pescado: Uma forma interessante de aproveitamento de resíduos do processamento de peixes. Revista Eletrônica Nutrime. v. 5, n. 4, Minas Gerais, 2008.

PIRES, D. R. et al. Aproveitamento do resíduo comestível do pescado: Aplicação e viabilidade. Revista Verde de Agroecologia e Desenvolvimento Sustentável, v. 9, n. 5, p. 34-46, 2014.

PRENTICE-HERNÁdEZ, C. Óleo de Pescado. In: GONÇALVES, A. A. Tecnologia do pescado: ciência, tecnologia, inovação e legislação. São Paulo. p.608. 2011.

QUAN, H. et al. Mechanism of anti-angiogenic activities of chitooligosaccharides may be through inhibiting heparanase activity. Medical Hypotheses, v. 73, p. 205-206, 2009.

RADZIEMSKA, M. et al. Valorização de composto de dejetos de pescado como fertilizante para uso agrícola. Valorização de Resíduos e Biomassa, v. 10, n. 9, pág. 2537-2545, 2019.

REBOUÇAS, M. C. et al. Caracterização do concentrado proteico de peixe obtido a partir dos resíduos da filetagem da tilápia do Nilo. Semina: Ciências Agrárias, v.33, n.2, p.697-704, 2012.

ROCHA, J.B.S. et al. Composição e estabilidade de farinha de tilápia (Oreochromis niloticus) produzida artesanalmente para o consumo humano. Magistra, v. 23, n. 4, p. 215-220, 2011.

RODRIGUES, L. O. et al. Produção de biofilme de quitosana, reduzida da quitina, extraída de exoesqueleto de crustáceos: proposta e disponibilização sustentável. Brazilian Applied Science Review, v. 4, n. 1, p. 218-239, 2020.

ROMAN, C.P. et al. Evaluación de procesos para obtener ensilaje de residuos piscícolas para alimentación animal. Ciencia en Desarrollo, v.8, n.2, p.39-50, 2017.

SALES, R.O.; OLIVEIRA, A.C. Evaluation of chemical composition, mineral, amino acid profile and fatty acid acid silage of Nile tilapia Oreochromis niloticus (Linnaeus) cultured in Indaiatuba - SP 1. Brazilian Journal of Hygiene and Animal Sanity, v.9, n.3, 2015.

SANES, F. S. M. et al. Compostagem e fermentação de resíduos de pescado para a produção de fertilizantes orgânicos. Semina: Ciências Agrárias, v. 36, n.3, p.1241-1252, 2015.

SIGNOR, F. R. P. et al. Increase in the nutritional quality of tilapia mechanically separated meat and application in fish patties. Brazilian Journal of Development, v. 6, n. 7, p. 47047-47061, 2020.

SHANKAR, T. J. et al. Storage Properties of Low Fat Fish and Rice Flour Coextrudates. Food and Bioprocess Technology, v.3, n.4, p.481-490, 2010.

SHIRAHIGUE, L. D. et al. The feasibility of increasing lipid extraction in Tilapia (Oreochromis niloticus) waste by proteolysis. Journal of Aquatic Food Product Technology, 25, 265-271, 2016. 
SILVA, C. M., DOS SANTOS DA FONSECA, R. A., \& PRENTICE, C. Comparing the hydrolysis degree of industrialization byproducts of Withemouth croaker (Micropogonias furnieri) using microbial enzymes. International Food Research Journal, v. 21, n. 5,p. 1757-1761, 2014.

SILVA, M. F. da. Elaboração e caracterização de silagem ácida de resíduos de tambaqui (Colossoma macropomum). Dissertação de Mestrado. Manaus. 2016.

SARTORI, A. G. DE O. \& AMANCIO, R. D. Pescado: importância nutricional e consumo no Brasil. Segur Alim Nutr, v.19, n. 2, p. 83-93, 2012.

SOARES, K. M. D. P. \& GONÇALVES, A. A. Seafood quality and safety. Revista do Instituto Adolfo Lutz, v. 71, n. 1, p. 1-10, 2012.

SOFIA. The State of World Fisheries and Aquaculture 2020 - Meeting the sustainable development goals. Rome, 2020.

SOUZA, M. L. R. Tecnologia para processamento das peles de peixes. Maringá: EDUEM, 2010.

SUCASAS, L. F. A. Avaliação do resíduo do processamento de pescado e desenvolvimento de co-produtos visando o incremento da sustentabilidade da cadeia produtiva. 2011. 166f. Tese de Doutorado (Doutorado em Ciências). Universidade de São Paulo, São Paulo.

TAHERGORABI, R. et al. Chemical properties of $\mathrm{x}-3$ fortified gels made of protein isolate recovered with isoelectric solubilisation/precipitation from whole fish. Food Chemistry, n.139, p.777-785, 2013.

TANTIKITTI, C. Palatabilidade da ração e as fontes alternativas de proteína na alimentação de camarões. Songklanakarin Journal of Science and Technology, v. 36, n. 1, p. 51-55, 2014.

TORRES S.M.; PEREIRA, F.D.A.R.; SOUZA, C.C.D.; FERREIRA, M.B. Análise da eficiência da produção da piscicultura na região de Dourados - MS. Rev Espacios, v. 38 n. 52, 2017.

TRISTÃO, F.A.; CALDERÓN, B.R.S.; REMBISKI, F.D. Utilização das conchas de mexilhão para a fabricação de cal para produção de argamassas históricas. In: Encontro Nacional, 5, e Encontro Latino-Americano, 3, sobre Edificações e Comunidades Sustentáveis, 2009, Recife. Resumos... Recife: ANTAC, 2009. p.

VÁZQUEZ, J. A. et al. Produção de compostos valiosos e metabólitos bioativos de subprodutos de descartes de peixes usando processamento químico, hidrólise enzimática e fermentação bacteriana. Drogas marinhas , v. 17, n. 3, pág. 139, 2019.

VEIT, J. C. et al. Desenvolvimento e caracterização de bolos de chocolate e de cenoura com filé de tilápia do Nilo (Oreochromis niloticus). Alimentos e Nutrição, v.23, n.3, p.427-433, 2012. 
VIDOTTI, R. M. Silagem de Pescado. In: Alex Augusto Gonçalves. (Org.). Tecnologia do Pescado. São Paulo: Atheneu, 2011. p. 399 - 406.

VIDOTTI, R.M.; GONÇALVES, G.S. Produção e caracterização de silagem, farinha e óleo de tilápia e sua utilização na alimentação animal. Boletim do Instituto de Pesca, 2006.

YANG, E.J.; KIM, J.G.; KIM, J.Y.; KIM, S.; LEE, N. Anti-inflammatory effect of chitosan oligosaccharides in RAW 264.7 cells. Central European Journal of Biology, v.5, p. 95-102, 2010 .

YUVARAJ, D. et al.. Production of biofuels from fish wastes: An overview. Biofuels, v.10, n. 3, 301-307, 2019

ZAMORA-SILLERO J, GHARSALLAOUI A, PRENTICE C: Peptides from fish by-product protein hydrolysates and its functional properties: an overview. Mar Biotechnol, 20:118-130, 2018.

ZANARDI, M.F. et al. Desempenho produtivo e reversão sexual em tilápias em dois métodos hormonal. Revista Medicina Veterinária e Zootecnia, v.18, p.45-52, 2011. 